\title{
Dynamic Optimal Control Differential Game of Ecological Compensation for Multipollutant Transboundary Pollution
}

\author{
Zhigang Chen $\mathbb{D}^{1},{ }^{1}$ Qianyue Meng $\mathbb{D}^{1},{ }^{1}$ Huichuan Wang, ${ }^{1}$ Rongwei Xu ${ }^{(D)},{ }^{1}$ Yongxi Yi, \\ and Ying Zhang ${ }^{1}$ \\ ${ }^{1}$ Institute of Regional and Urban-Rural Development, Wuhan University, Wuhan, China \\ ${ }^{2}$ School of Economics, Management \& Law, University of South China, Hengyang, China \\ Correspondence should be addressed to Rongwei Xu; rongwei_xu188@126.com
}

Received 20 February 2021; Revised 29 May 2021; Accepted 21 June 2021; Published 2 July 2021

Academic Editor: Honglei Xu

Copyright (C) 2021 Zhigang Chen et al. This is an open access article distributed under the Creative Commons Attribution License, which permits unrestricted use, distribution, and reproduction in any medium, provided the original work is properly cited.

\begin{abstract}
This paper studies a Stackelberg differential game between an upstream region and a downstream region for transboundary pollution control and ecological compensation in a river basin and increases the number of pollutants assumed in the model to multiple. Emission and green innovation investment between upstream and downstream regions in the same basin is a Stackelberg game, and the downstream region provides economic compensation for green innovation investment in the upstream region. The results show that there is an optimal ecological compensation rate, and a Pareto improvement result can be obtained by implementing ecological compensation. Increasing the proportion of ecological compensation can improve the nonvirtuous chain reaction between green innovation investment cost, pollutant transfer rate, and ecological compensation rate. Therefore, it is necessary to establish a joint mechanism composed of the government and the market and formulate a reasonable green innovation subsidy scheme according to the actual situation of the basin, so as to restrict the emergence of this "individual rational" behavior. For river basin areas that can establish a unified management department and organize the implementation of decisionmaking, the cooperative game is a very effective pollution control decision.
\end{abstract}

\section{Introduction}

Since the late 1970s, the application of differential game theory has flourished in management science and economics. Relevant research covers economics, industrial organization, oligarchy theory, resource and environmental economics, labor economics, marketing, production and operation management, finance, innovation, and many more. Dockner et al. [1] comprehensively introduced the basic principles and applications of differential game theory. Starting from the differential game theory, this paper analyzes the basic knowledge needed to establish the model and then expounds the practical operation of the theory in the field of economics and management. Sana [2] dealt with an inventory model to determine the retailer's optimal order quantity for similar products. Jorgensen and Zaccour [3] reviewed the literature on the differential game theory method used in cooperative advertising in marketing channels (supply chain). Cabo et al. [4] analyzed the sustainability of economic growth in a dynamic two country trade model. Janssens and Zaccour [5] studied how to determine the optimal price, subsidy path, and strategic decision of emerging industries such as solar energy under budget constraints. Shib [6] established a differential game model to study the optimal solution and pricing of drug sales team. Andres Domenech et al. [7] simulated the impact of forest depletion on carbon dioxide accumulation in the atmosphere, considering that forest owners use forest resources to obtain wood and deforestation to obtain economic benefits in the form of agriculture, while causing negative externalities to nonowners. Petrosyan and Zaccour [8] believed that it is individual and collective rationality for the participants to sign long-term cooperation agreements. Bhattacharyya and Sana [9] dealt with a mathematical model of the production inventory system of green products in a green manufacturing industry. Then, Roy et al. [10] studied a 
two-echelon supply chain comprising of one manufacturer and two competing retailers with sales price dependent demand and random arrival of the customers. Sana [11] dealt with a newsvendor inventory model in light of green product marketing of corporate social responsible firms and analyzed including subsidy and tax implementation by the Government. Sana [12] used differential game theory to analyze two green supply chain system models.

The problem of transboundary pollution arises with the development of industrialization and has become a research focus since the 1990s. For example, Ploeg et al. [13] assumed that participants use a linear Markov perfect strategy and developed a differential game model to probe into the transboundary pollution issue, by which the cooperative and noncooperative Nash equilibrium results are reached. Long [14] investigated an international transboundary pollution game and found that the symmetric open-loop Nash equilibrium yields more pollution than in the case of the players use cooperative strategy. Extending the research of Long [14], Dockner and Long [15] showed that, in the transboundary pollution games, noncooperative behavior will result in welfare loss for both countries. Petrosyan and Zaccour [16] devoted the fair distribution of the total cost resulting in the cooperation in transboundary pollution control. Following the idea of Petrosyan and Zaccour [16], Jørgensen and Zaccour [17] investigated the distribution of cooperative residual benefits, and a payment distribution mechanism supporting the subgame consistent solution is given. Yeung [18] first derived the time-consistent solutions in a cooperative differential game and studied the pollution management in a stochastic differential game framework. Immediately afterwards, in paper [19], a cooperative stochastic differential game of transboundary industrial pollution is presented, and a payment distribution mechanism is derived to maintain the subgame consistency. Benchekroun and Martín-Herran [20] explored the effects of foresight in a transboundary pollution game, and they showed an interesting result that, in the case where one myopic country becomes farsighted, the welfare levels will not necessarily increase. Li [21] developed a transboundary pollution differential game model in which the emission permitted trading is taken into account. Huang et al. [22] developed a model in which there is a Stackelberg game between the industrial firms and their local government, while the governments can cooperate in transboundary pollution control. Chang et al. [23] investigated the optimal pollution abatement strategies of two countries involved in transboundary pollution under cooperative and noncooperative games. Additionally, there are several published studies of transboundary pollution problems from other views, such as renewable resources, clean technologies, harmonization of international and domestic law, abatement cost, and R\&D spillovers (for instance, [24-30]).

Ecological compensation refers to a case that the investment cost of environmental governance is shouldered in part or in whole by the one who enjoys the benefits of environmental improvement or government [31]. It is estimated that ecological compensation is an efficient instrument in cooperative environmental pollution control
[32]. However, the research literatures above mentioned on transboundary pollution control do not consider the ecological compensation issue. Until recently, Jiang et al. [33] investigated a transboundary pollution control gaming with ecological compensation in a river basin. In the model of Jiang et al. [33], the upstream region as the leader of the Stackelberg game is responsible for pollution abatement, and the downstream region as the follower compensates the upstream region for her abatement investment in part. In fact, this paper can be viewed as an extension of Jiang et al. [33]. Differences from Jiang et al. [33] are as follows: (i) it is not just the upstream region; in our model, both the upstream region and downstream region in a river basin can invest in pollution abatement (green innovation). (ii) Different from the model of Jiang et al. [33], in our model, the leader of the game is the downstream region who determines the ecological compensation rate firstly, then the follower, e.g., the upstream region, decides the abatement investment under the given compensation rate. (iii) In our model, we also consider the learning effect of two regions through green innovation investment to improve efficiency and reduce costs. The positive effects of learning by doing have been widely studied since Arrow [34]. He thought that a good index of the stock of knowledge is the cumulative investment. Recently, Li and Pan [35] investigated the pollution abatement issue in which the experience using pollution abatement technology is measured by the cumulative abatement from time 0 to $t$; this may be the first time that the cost-reducing learning by doing in cumulative investment is taken into account. To expand the thinking of Li [21], in this paper, we examine the effects of efficiencyimproving and cost-reducing learning by doing in green innovation simultaneously. The reason for taking efficiencyimproving learning by doing into account is that the phenomenon of efficiency-improving learning by doing is real, and it is widely accepted [36]. To some extent, it can be called "skill comes by exercise" or "practice makes perfect." Grosse et al. [37] argued that performance improvements of individuals, groups, or organizations over time are a result of accumulated experience.

However, the research on the treatment of transboundary water pollution based on river basins and the search for effective methods to solve the integrated management have also become the goal pursued by many researchers. How to scientifically and effectively coordinate the interests of the participating entities in the river basin, optimize the water environment planning, and fully solve the problem of water pollution has become the key to the prevention and control of transboundary water pollution. Studying the problem of transboundary water pollution prevention, control from the level of cross-regional coordination, and cooperation in the river basin and seeking solutions to the problem of water pollution control have important practical significance for solving regional water environmental problems.

The rest of this paper is organized as follows. In Section 2 , we will establish our basic dynamic general equilibrium model. The strategies of both the upstream region and the downstream region are achieved in Section 3 and Section 4. 
Some discussions are provided with several numerical examples and policy implications in Section 5. Finally, Section 6 concludes the paper.

\section{The Necessary Assumptions and Establishment of the Model}

2.1. The Basic Assumptions of the Model. Let us start out with a simple but widely used assumption in a related study ( $\mathrm{Li}$ and Guo [38]) that a river basin consists of only two regions, upstream and downstream, denoted by subscripts $i$, $i=1$ and 2 . In addition, both regions produce an identical consumed good with an identical and given fixed endowment of production factors and an identical and given technology over continuous time $t \in(0, \infty)$. Moreover, in order for the model to accommodate the study of multipollutant transboundary pollution, it is assumed that the production process in the two regions is accompanied by the emission of two kinds of pollutants identified by subscripts $j$, $j=1$ and 2. Further, there is a close relationship of both regions' revenue $R_{i}(\cdot)$ and the amount of the pollutants $e_{i j}(\cdot)$ given as

$$
R_{i}\left(e_{i 1}(t), e_{i 2}(t)\right)=\alpha_{i 1} e_{i 1}^{1 / 2}(t)+\alpha_{i 2} e_{i 2}^{1 / 2}(t),
$$

where $i=1$ and $2, j=1$ and 2 , and $\alpha_{i 1}>0$ and $\alpha_{i 2}>0$ are constant which measure the marginal contribution of the amount of pollutants of region $i$. From (1), one can see that $\left(R_{i 1}\right)^{\prime}>0$ and $\left(R_{i 2}\right)^{\prime}>0$, which signify that an increase in any one pollutant will increase the revenue of the region but may be $\mathrm{d} R_{i}(\cdot) / \mathrm{d} e_{i 1} \neq \mathrm{d} R_{i}(\cdot) / \mathrm{d} e_{i 2}$ because may be $\alpha_{i 1} \neq \alpha_{i 2}$. So, the amount of each pollutant should be weighed by the region $i, i=1$ and 2. In addition, (1) shows $\left(R_{i j}\right)^{\prime \prime}<0$, which means the marginal contribution of each pollutant to returns is diminishing.

Next, consider both regions' stock evolution of the two pollutants $\dot{S}_{1 j}(t)$ and $\dot{S}_{2 j}(t)$ with time $t$. Assume they are given by

$$
\begin{aligned}
& \dot{S}_{1 j}(t)=e_{1 j}(t)-x_{1 j}(t)-\delta_{1 j} S_{1 j}(t)-\phi_{1 j} S_{1 j}(t), \\
& \dot{S}_{2 j}(t)=e_{2 j}(t)-x_{2 j}(t)-\delta_{2 j} S_{2 j}(t)+\phi_{1 j} S_{1 j}(t),
\end{aligned}
$$

where $\delta_{1 j}>0$ and $\delta_{2 j}>0$ indicate the natural decay rate of emissions of both regions. $\phi>0$ stands for the transfer coefficient of pollution from the upstream region to the downstream region. Dynamic equations (2) and (3) imply that the pollution can be abated linearly by the green innovation investment $x_{1 j}(t)$ and $x_{2 j}(t)$ carried out by the upstream region and downstream region, respectively. Further, inquire the abatement investment cost $C_{i}\left(x_{i 1}(t), x_{i 2}(t)\right)$. Assume there are following equations:

$$
C_{i}\left(x_{i 1}(t), x_{i 2}(t)\right)=\beta_{i 1} x_{i 1}^{2}+\beta_{i 2} x_{i 2}^{2},
$$

where $\beta_{i 1}>0$ and $\beta_{i 2}>0$ are constant. (4) shows that $\mathrm{d} C_{i}(\cdot) / \mathrm{d} x_{i 1}(t)>0$ and $\mathrm{d} C_{i}(\cdot) / \mathrm{d} x_{i 2}(t)>0$ which mean that investment in each pollutant reduction incurs an increase in total cost. In addition, the second derivative $d^{2} C_{i}(\cdot) /$ $d\left(x_{i 1}(t)\right)^{2}>0$ and $d^{2} C_{i}(\cdot) / d\left(x_{i 2}(t)\right)^{2}>0$ indicate that the marginal cost of abatement investment is rising.

Following Lambertini and Mantovani [39] and Guiomar et al. [40], assume that both regions are damaged by the stock of pollution, and we assume that there exists the following pollution damage function:

$$
D_{i}\left(S_{i 1}(t), S_{i 2}(t)\right)=\theta_{i 1} S_{i 1}(t)+\theta_{i 2} S_{i 2}(t),
$$

where $\theta_{i 1}>0$ and $\theta_{i 2}>0$ measure the marginal impact of the stock of pollution $S_{i 1}(t)$ and $S_{i 2}(t)$. In addition, we assume $\theta_{i 1} \neq \theta_{i 2}$ and $\theta_{1 j} \neq \theta_{2 j} . \theta_{i 1} \neq \theta_{i 2}$ means that the two pollutants have different properties, so the marginal effects of the two pollutants on the same region are different. $\theta_{1 j} \neq \theta_{2 j}$ says that the marginal effects of the same pollutant on different regions are different due to the difference of the economic development level. It is generally assumed that the more developed the economy, the greater the marginal effects of pollution damage on the region.

A final but crucial assumption is that, in order to encourage the upstream region to invest in green innovation for reducing the quantity of transferring pollution from the upstream region to the downstream region, we suppose that the downstream region is willing to compensate the upstream region for her investment in green innovation with compensation rate $\tau$.

2.2. The Establishment of the Differential Game Model. According to differential game theory, the objective of the upstream region is to find the optimal green innovation investment $x_{1 j}, j=1$ and 2 , and the optimal quantity of emissions quantity $e_{1 j}, j=1$ and 2 , to maximize following discounted revenue flow over the continuous time $t$, $t \in[0, \infty)$ :

$$
\begin{array}{r}
W_{1}=\max _{e_{11}, e_{12}, x_{11}, x_{12}} \int_{0}^{\infty} e^{-r t}\left[\begin{array}{c}
R_{1}\left(e_{11}(t), e_{12}(t)\right)-(1-\tau) C_{1}\left(x_{11}(t), x_{12}(t)\right) \\
-D_{1}\left(S_{11}(t), S_{12}(t)\right)
\end{array}\right] \mathrm{d} t, \\
\text { S.t }\left\{\begin{array}{l}
\dot{S}_{11}(t)=e_{11}(t)-x_{11}(t)-\delta_{11} S_{11}(t)-\phi_{11} S_{11}(t), \\
\dot{S}_{12}(t)=e_{12}(t)-x_{12}(t)-\delta_{12} S_{12}(t)-\phi_{12} S_{12}(t) .
\end{array}\right.
\end{array}
$$


Similarly, the optimization problem of the downstream region can be given as

$$
\begin{aligned}
& W_{2}=\max _{e_{21}, e_{22}, x_{21}, x_{22}} \int_{0}^{\infty} e^{-r t}\left[\begin{array}{c}
R_{2}\left(e_{21}(t), e_{22}(t)\right)-\tau C_{1}\left(x_{11}(t), x_{12}(t)\right) \\
-C_{2}\left(x_{21}(t), x_{22}(t)\right)-D_{2}\left(S_{21}(t), S_{22}(t)\right)
\end{array}\right] \mathrm{d} t, \\
& \text { S.t }\left\{\begin{array}{l}
\dot{S}_{21}(t)=e_{21}(t)-x_{21}(t)-\delta_{21} S_{21}(t)+\phi_{11} S_{11}(t), \\
\dot{S}_{22}(t)=e_{22}(t)-x_{22}(t)-\delta_{22} S_{22}(t)+\phi_{12} S_{12}(t) .
\end{array}\right.
\end{aligned}
$$

Visibly, the game between the upstream region and the downstream region in the river basin is a Stackelberg game in which the downstream region as the leader decides the compensation rate $\tau$ at first and then the upstream region as the follower determines her green innovation investment under the given compensation rate. In the next section, we will apply the backward induction to solve the optimization problems of both regions.

\section{Decision-Making Choice of Noncooperative Game in Upstream and Downstream}

3.1. The Upstream Region's Optimal. The upstream as the follower of the Stackelberg game determines her optimal strategy under the given compensation rate $\tau$ decided by the leader, e.g., the downstream region. From (6), the following current-value Hamiltonian can be obtained:

$$
\begin{aligned}
H_{1}= & R_{1}\left(e_{11}(t), e_{12}(t)\right)-(1-\tau) C_{1}\left(x_{11}(t), x_{12}(t)\right)-D_{1}\left(S_{11}(t), S_{12}(t)\right)+\lambda_{11}\left(e_{11}(t)-x_{11}(t)-\delta_{11} S_{11}(t)-\phi_{11} S_{11}(t)\right) \\
& +\lambda_{12}\left(e_{12}(t)-x_{12}(t)-\delta_{12} S_{12}(t)-\phi_{12} S_{12}(t)\right),
\end{aligned}
$$

where $\lambda_{11}$ and $\lambda_{12}$ are dynamic costate variables measuring the shadow prices of the associated state equations $\dot{S}_{11}(t)$ and $\dot{S}_{12}(t)$, respectively.

From the first-order conditions, costate conditions, and state equation of current-value Hamiltonian (8), following dynamic system (9) can be written out:

$$
\left\{\begin{array}{l}
\dot{S}_{11}(t)=e_{11}(t)-x_{11}(t)-\left(\delta_{11}+\phi_{11}\right) S_{11}(t), \\
\dot{S}_{12}(t)=e_{12}(t)-x_{12}(t)-\left(\delta_{12}+\phi_{12}\right) S_{12}(t), \\
\dot{e}_{11}(t)=-2\left(r+\delta_{11}+\phi_{11}\right) e_{11}(t)+\frac{4 \theta_{11}}{\alpha_{11}} e_{11}^{3 / 2}(t), \\
\dot{e}_{12}(t)=-2\left(r+\delta_{12}+\phi_{12}\right) e_{12}(t)+\frac{4 \theta_{12}}{\alpha_{12}} e_{12}^{3 / 2}(t), \\
\dot{x}_{11}(t)=\frac{2 \beta_{11}(1-\tau)\left(r+\delta_{11}+\phi_{11}\right) x_{11}(t)-\theta_{11}}{2 \beta_{11}(1-\tau)}, \\
\dot{x}_{12}(t)=\frac{2 \beta_{12}(1-\tau)\left(r+\delta_{12}+\phi_{12}\right) x_{12}(t)-\theta_{12}}{2 \beta_{12}(1-\tau)} .
\end{array}\right.
$$

To obtain the general managerial insight, we devote our mind to the steady state equilibrium. If there do exists a steady state equilibrium, let us apply the superscript " $\wedge$ " to identify the noncooperative equilibrium results. Solving (9) under state equilibrium conditions, we get

$$
\begin{aligned}
& \hat{e}_{11}=\left(\frac{\alpha_{11}\left(r+\delta_{11}+\phi_{11}\right)}{2 \theta_{11}}\right)^{2}, \\
& \widehat{e}_{12}=\left(\frac{\alpha_{12}\left(r+\delta_{12}+\phi_{12}\right)}{2 \theta_{12}}\right)^{2}, \\
& \hat{x}_{11}=\frac{\theta_{11}}{2 \beta_{11}(1-\tau)\left(r+\delta_{11}+\phi_{11}\right)}, \\
& \widehat{x}_{12}=\frac{\theta_{12}}{2 \beta_{12}(1-\tau)\left(r+\delta_{12}+\phi_{12}\right)}, \\
& \widehat{S}_{11}=\frac{\alpha_{11}^{2} \beta_{11}(1-\tau)\left(r+\delta_{11}+\phi_{11}\right)^{3}-2 \theta_{11}^{3}}{4 \theta_{11}^{2} \beta_{11}(1-\tau)\left(\delta_{11}+\phi_{11}\right)\left(r+\delta_{11}+\phi_{11}\right)}, \\
& \widehat{S}_{12}=\frac{\alpha_{12}^{2} \beta_{12}(1-\tau)\left(r+\delta_{12}+\phi_{12}\right)^{3}-2 \theta_{12}^{3}}{4 \theta_{12}^{2} \beta_{12}(1-\tau)\left(\delta_{12}+\phi_{12}\right)\left(r+\delta_{12}+\phi_{12}\right)},
\end{aligned}
$$

where $\widehat{e}_{11}$ represents the optimal strategy selection of pollutant 1 emission rate in the upstream region of the basin in the noncooperative game decision model, $\widehat{e}_{12}$ represents the optimal emission rate of pollutant $2, \widehat{x}_{11}$ and $\widehat{x}_{12}$ represent the optimal green innovation investment choices for pollutants 1 and 2 in the upstream region, respectively, $\widehat{S}_{11}$ represents the stock level of upstream pollutant 1 under the condition of noncooperative game decision, and $\widehat{S}_{12}$ represents the stock level of pollutant 2 . The above results reflect the optimal strategy choice of noncooperative game decision-making in the basin. That is to say, in practice, the upstream of the river basin adopt the optimal Nash 
equilibrium strategy for themselves after receiving a certain amount of green innovation subsidies from the downstream.

3.2. The Downstream Region's Optimal. As the leader, the downstream region sets the compensation rate $\tau$ and decides her green innovation investment $x_{21}(t)$ and $x_{22}(t)$ to maximize her benefits. Note, when the downstream region is set the compensation rate, she must take into account the response of the upstream region. We obtain current-value Hamiltonian from (7) as follows:

$$
\begin{aligned}
H_{2}= & R_{2}\left(e_{21}(t), e_{22}(t)\right)-\tau C_{1}\left(x_{11}(t), x_{12}(t)\right)-C_{2}\left(x_{21}(t), x_{22}(t)\right)-D_{2}\left(S_{21}(t), S_{22}(t)\right) \\
& +\lambda_{21}(t)\left(e_{21}(t)-x_{21}(t)-\delta_{21} S_{21}(t)+\phi_{11} S_{11}(t)\right)+\lambda_{22}(t)\left(e_{22}(t)-x_{22}(t)-\delta_{22} S_{22}(t)+\phi_{12} S_{12}(t)\right) .
\end{aligned}
$$

Using the first-order conditions, costate conditions, and state equation of current-value Hamiltonian (11), the following dynamic system is achieved:

$$
\left\{\begin{array}{l}
\dot{S}_{21}(t)=e_{21}(t)-x_{21}(t)-\delta_{21} S_{21}(t)+\phi_{11} S_{11}(t), \\
\dot{S}_{22}(t)=e_{22}(t)-x_{22}(t)-\delta_{22} S_{22}(t)+\phi_{12} S_{12}(t), \\
\dot{e}_{21}(t)=-2\left(r+\delta_{21}\right) e_{21}(t)+\frac{4 \theta_{21}}{\alpha_{21}} e_{21}^{3 / 2}(t), \\
\dot{e}_{22}(t)=-2\left(r+\delta_{22}\right) e_{22}(t)+\frac{4 \theta_{22}}{\alpha_{22}} e_{22}^{3 / 2}(t), \\
\dot{x}_{21}(t)=\frac{2 \beta_{21}\left(r+\delta_{21}\right) x_{21}(t)-\theta_{21}}{2 \beta_{21}}, \\
\dot{x}_{22}(t)=\frac{2 \beta_{22}\left(r+\delta_{22}\right) x_{22}(t)-\theta_{22}}{2 \beta_{22}}
\end{array}\right.
$$

Under steady state equilibrium conditions, solving dynamic system (12), the following noncooperative equilibrium results of the downstream region are reached:

$$
\begin{aligned}
& \hat{e}_{21}=\left(\frac{\alpha_{21}\left(r+\delta_{21}\right)}{2 \theta_{21}}\right)^{2}, \\
& \hat{e}_{22}=\left(\frac{\alpha_{22}\left(r+\delta_{22}\right)}{2 \theta_{22}}\right)^{2}, \\
& \widehat{x}_{21}=\frac{\theta_{21}}{2 \beta_{21}\left(r+\delta_{21}\right)}, \\
& \widehat{x}_{22}=\frac{\theta_{22}}{2 \beta_{22}\left(r+\delta_{22}\right)}, \\
& \widehat{S}_{21}=\frac{e_{21}-x_{21}+\phi_{11} \widehat{S}_{11}}{\delta_{21}}, \\
& \widehat{S}_{22}=\frac{e_{22}-x_{22}+\phi_{12} \widehat{S}_{12}}{\delta_{22}},
\end{aligned}
$$

where $\widehat{e}_{21}$ represents the optimal strategy selection of pollutant 1 emission rate in the downstream region of the basin in the noncooperative game decision model, $\widehat{e}_{22}$ represents the optimal emission rate of pollutant $2, \widehat{x}_{21}$ and $\hat{x}_{22}$ represent the optimal green innovation investment choices for pollutants 1 and 2 in the downstream region, respectively, 
$\widehat{S}_{21}$ represents the stock level of downstream pollutant 1 under the condition of noncooperative game decision, and $\widehat{S}_{22}$ represents the stock level of pollutant 2 . The above results reflect the optimal strategy choice of noncooperative game decision-making in the basin. That is to say, in practice, the downstream of the basin, after subsidizing a certain amount of green innovation in the upstream, adopt the optimal Nash equilibrium strategy for themselves.

Next, we solve the optimal compensation rate $\tau$. From (7), we get downstream region's value function (14) under steady state equilibrium conditions:

$$
\widetilde{U}_{2}(\tau)=\alpha_{21} \widetilde{e}_{21}^{1 / 2}(\tau)+\alpha_{22} \widetilde{e}_{22}^{1 / 2}(\tau)-\tau\left[\beta_{11} \widetilde{x}_{11}^{2}(\tau)+\beta_{12} \widetilde{x}_{12}^{2}(\tau)\right]-\left[\beta_{21} \widetilde{x}_{21}^{2}(\tau)+\beta_{22} \widetilde{x}_{22}^{2}(\tau)\right]-\left[d_{21} \widetilde{S}_{21}(\tau)+d_{22} \widetilde{S}_{22}(\tau)\right] .
$$

Substituting the results reached in (8) and (9) and applying the first-order conditions $\partial U_{2}(\tau) / \partial \tau=0$, we obtain following equation:

$\tau^{*}=\frac{\left\{\beta_{12} \delta_{22} \theta_{11}\left(\delta_{12}+\phi_{12}\right)\left(r+\delta_{12}+\phi_{12}\right)^{2}\left[2 \phi_{11} \theta_{21}\left(r+\delta_{11}+\phi_{11}\right)-\delta_{21} \theta_{11}\left(\delta_{11}+\phi_{11}\right)\right]+\beta_{11} \delta_{21} \theta_{12}\left(\delta_{11}+\phi_{11}\right)\left(r+\delta_{11}+\phi_{11}\right)^{2}\left[2 \phi_{12} \theta_{22}\left(r+\delta_{12}+\phi_{12}\right)-\delta_{22} \theta_{12}\left(\delta_{12}+\phi_{12}\right)\right]\right\}}{\left\{\beta_{12} \delta_{22} \theta_{11}\left(\delta_{12}+\phi_{12}\right)\left(r+\delta_{12}+\phi_{12}\right)^{2}\left[\delta_{21} \theta_{11}\left(\delta_{11}+\phi_{11}\right)+2 \phi_{11} \theta_{21}\left(r+\delta_{11}+\phi_{11}\right)\right]+\beta_{11} \delta_{21} \theta_{12}\left(\delta_{11}+\phi_{11}\right)\left(r+\delta_{11}+\phi_{11}\right)^{2}\left[\delta_{22} \theta_{12}\left(\delta_{12}+\phi_{12}\right)+2 \phi_{12} \theta_{22}\left(r+\delta_{12}+\phi_{12}\right)\right]\right\}}$

Here, $\tau^{*}$ represents the optimal green innovation subsidy rate, that is, the benefit compensation rate when the upstream and downstream regions of the basin can reach the optimal Nash equilibrium.

\section{Decision-Making Choice of Cooperative Game in Upstream and Downstream}

Under a cooperative framework, the common goal of the two regions is to maximize the discounted stream of net present joint returns $W_{1}+W_{2}$ by controlling the quantity of emissions $e_{11}(t), e_{12}(t), e_{21}(t)$, and $e_{22}(t)$ as well as the investment level of green innovation $x_{11}(t), x_{12}(t), x_{21}(t)$, and $x_{22}(t)$ over continuous time $t, t \in[0, \infty)$, namely,

$$
\begin{aligned}
& W_{1}+W_{2}= \max _{e_{11}, e_{12}, x_{11}, x_{12}} \int_{0}^{\infty} e^{-r t}\left[\begin{array}{c}
R_{1}\left(e_{11}(t), e_{12}(t)\right)+R_{2}\left(e_{21}(t), e_{22}(t)\right) \\
-C_{1}\left(x_{11}(t), x_{12}(t)\right)-C_{2}\left(x_{21}(t), x_{22}(t)\right) \\
-D_{1}\left(S_{11}(t), S_{12}(t)\right)-D_{2}\left(S_{21}(t), S_{22}(t)\right)
\end{array}\right] \mathrm{d} t, \\
& \text { S.t }\left\{\begin{array}{l}
\dot{S}_{11}(t)=e_{11}(t)-x_{11}(t)-\delta_{11} S_{11}(t)-\phi_{11} S_{11}(t), \\
\dot{S}_{12}(t)=e_{12}(t)-x_{12}(t)-\delta_{12} S_{12}(t)-\phi_{12} S_{12}(t), \\
\dot{S}_{21}(t)=e_{21}(t)-x_{21}(t)-\delta_{21} S_{21}(t)+\phi_{11} S_{11}(t), \\
\dot{S}_{22}(t)=e_{22}(t)-x_{22}(t)-\delta_{22} S_{22}(t)+\phi_{12} S_{12}(t) .
\end{array}\right.
\end{aligned}
$$

There is the following current-value Hamiltonian:

$$
\begin{aligned}
H_{C}= & R_{1}\left(e_{11}(t), e_{12}(t)\right)+R_{2}\left(e_{21}(t), e_{22}(t)\right)-C_{1}\left(x_{11}(t), x_{12}(t)\right)-C_{2}\left(x_{21}(t), x_{22}(t)\right) \\
& -D_{1}\left(S_{11}(t), S_{12}(t)\right)-D_{2}\left(S_{21}(t), S_{22}(t)\right)+\chi_{11}(t)\left(e_{11}(t)-x_{11}(t)-\delta_{11} S_{11}(t)-\phi_{11} S_{11}(t)\right) \\
& +\chi_{12}(t)\left(e_{12}(t)-x_{12}(t)-\delta_{12} S_{12}(t)-\phi_{12} S_{12}(t)\right)+\chi_{21}(t)\left(e_{21}(t)-x_{21}(t)-\delta_{21} S_{21}(t)+\phi_{11} S_{11}(t)\right) \\
& +\chi_{22}(t)\left(e_{22}(t)-x_{22}(t)-\delta_{22} S_{22}(t)+\phi_{12} S_{12}(t)\right),
\end{aligned}
$$


where $\chi_{11}(t), \chi_{12}(t), \chi_{21}(t)$, and $\chi_{22}(t)$ are the costate variables which correspond to the state variables $S_{11}(t), S_{12}(t)$, $S_{21}(t)$, and $S_{22}(t)$.

Through the first-order conditions, costate conditions, and constraint equations of current-value Hamiltonian (17), we yield the following dynamic systems:

$$
\begin{aligned}
& \left\{\begin{array}{l}
\dot{S}_{11}(t)=e_{11}(t)-x_{11}(t)-\delta_{11} S_{11}(t)-\phi_{11} S_{11}(t), \\
\dot{S}_{12}(t)=e_{12}(t)-x_{12}(t)-\delta_{12} S_{12}(t)-\phi_{12} S_{12}(t), \\
\dot{S}_{21}(t)=e_{21}(t)-x_{21}(t)-\delta_{21} S_{21}(t)+\phi_{11} S_{11}(t), \\
\dot{S}_{22}(t)=e_{22}(t)-x_{22}(t)-\delta_{22} S_{22}(t)+\phi_{12} S_{12}(t), \\
\dot{e}_{11}(t)=-2\left(r+\delta_{11}+\phi_{11}\right) e_{11}(t)-\frac{4\left(\phi_{11} \chi_{21}(t)-\theta_{11}\right) e_{11}^{3 / 2}(t)}{\alpha_{11}},
\end{array}\right. \\
& \dot{e}_{12}(t)=-2\left(r+\delta_{12}+\phi_{12}\right) e_{12}(t)-\frac{4\left(\phi_{12} \chi_{22}(t)-\theta_{12}\right) e_{12}^{3 / 2}(t)}{\alpha_{12}}, \\
& \dot{e}_{21}(t)=-2\left(r+\delta_{21}\right) e_{21}(t)+\frac{4 \theta_{21} e_{21}^{3 / 2}(t)}{\alpha_{21}}, \\
& \dot{e}_{22}(t)=-2\left(r+\delta_{22}\right) e_{22}(t)+\frac{4 \theta_{22} e_{22}^{3 / 2}(t)}{\alpha_{22}}, \\
& \dot{x}_{11}(t)=\frac{2 \beta_{11}\left(r+\delta_{11}+\phi_{11}\right) x_{11}(t)+\phi_{11} \chi_{21}(t)-\theta_{11}}{2 \beta_{11}}, \\
& \dot{x}_{12}(t)=\frac{2 \beta_{12}\left(r+\delta_{12}+\phi_{12}\right) x_{12}(t)+\phi_{12} \chi_{22}(t)-\theta_{12}}{2 \beta_{12}}, \\
& \dot{x}_{21}(t)=\frac{2 \beta_{21}\left(r+\delta_{21}\right) x_{21}(t)-\theta_{21}}{2 \beta_{21}}, \\
& \dot{x}_{22}(t)=\frac{2 \beta_{22}\left(r+\delta_{22}\right) x_{22}(t)-\theta_{22}}{2 \beta_{22}}, \\
& \dot{\chi}_{21}(t)=\left(r+\delta_{21}\right) \chi_{21}(t)+\theta_{21} \\
& \dot{\chi}_{22}(t)=\left(r+\delta_{22}\right) \chi_{22}(t)+\theta_{22} .
\end{aligned}
$$

Solving dynamic differential system (18) under the steady state condition and characterizing the steady state equilibrium solutions by superscript " ," following results are obtained:

$$
\begin{aligned}
& \tilde{e}_{11}=\left[\frac{\alpha_{11}\left(r+\delta_{21}\right)\left(r+\delta_{11}+\phi_{11}\right)}{2\left(\phi_{11} \theta_{21}+\theta_{11}\left(r+\delta_{21}\right)\right)}\right]^{2}, \\
& \tilde{e}_{12}=\left[\frac{\alpha_{12}\left(r+\delta_{22}\right)\left(r+\delta_{12}+\phi_{12}\right)}{2\left(\phi_{12} \theta_{22}+\theta_{12}\left(r+\delta_{22}\right)\right)}\right]^{2}, \\
& \tilde{e}_{21}=\left[\frac{\alpha_{21}\left(r+\delta_{21}\right)}{2 \theta_{21}}\right]^{2}, \\
& \tilde{e}_{22}=\left[\frac{\alpha_{22}\left(r+\delta_{22}\right)}{2 \theta_{22}}\right]^{2}, \\
& \tilde{x}_{11}=\frac{\left(r+\delta_{21}\right) \theta_{11}+\phi_{11} \theta_{21}}{2 \beta_{11}\left(r+\delta_{21}\right)\left(r+\delta_{11}+\phi_{11}\right)}, \\
& \tilde{x}_{12}=\frac{\left(r+\delta_{22}\right) \theta_{12}+\phi_{12} \theta_{22}}{2 \beta_{12}\left(r+\delta_{22}\right)\left(r+\delta_{12}+\phi_{12}\right)}, \\
& \tilde{x}_{21}=\frac{\theta_{21}}{2 \beta_{21}\left(r+\delta_{21}\right)}, \\
& \tilde{x}_{22}=\frac{\theta_{22}}{2 \beta_{22}\left(r+\delta_{22}\right)}, \\
& \tilde{S}_{11}=\frac{e_{11}-\tilde{x}_{11}}{\left(\delta_{11}+\phi_{11}\right)}, \\
& \tilde{S}_{12}=\frac{e_{12}-\tilde{x}_{12}}{\left(\delta_{12}+\phi_{12}\right)}, \\
& \tilde{S}_{21}-\tilde{x}_{21}+\phi_{11} \widetilde{S}_{11} \\
& \delta_{21}-\tilde{x}_{22}+\phi_{12} \widetilde{S}_{12} \\
& \delta_{22}
\end{aligned}
$$

\section{Numerical Examples and Policy Implications}

Through the analysis mentioned above, we have obtained the optimal emission, green innovation investment, and pollution stock under noncooperative game and cooperative game.

In this section, we will simulate and analyze the influencing factors and changes of the green innovation compensation rate, the change trajectory of each variable under different decision-making models, and further analysis. The parameters used in the numerical examples are presented in Table 1 and we use version 7.0 of Wolfram Mathematical MATLAB to obtain the numerical solutions. The parameters are as follows [41-43].

5.1. Green Innovation Compensation Rate. There is a positive relationship between the rate of ecological compensation and the coefficient of green innovation investment cost. As shown in Figure 1, the higher the green innovation 
TABLE 1: The parameters used in the numerical example.

\begin{tabular}{ccccccccccc}
\hline$\beta_{11}$ & $\beta_{12}$ & $\beta_{21}$ & $\beta_{22}$ & $\delta_{11}$ & $\delta_{12}$ & $\delta_{21}$ & $\delta_{22}$ & $\theta_{11}$ & $\theta_{12}$ & $\theta_{21}$ \\
\hline 0.5 & 0.55 & 0.4 & 0.45 & 0.12 & 0.1 & 0.12 & 0.1 & 0.2 & 0.25 & 0.2 \\
\hline$\theta_{22}$ & $\phi_{11}$ & $\phi_{12}$ & $\phi_{21}$ & $\phi_{22}$ & $\alpha_{11}$ & $\alpha_{12}$ & $\alpha_{21}$ & $\alpha_{22}$ & $r$ & \\
\hline 0.25 & 0.11 & 0.1 & 0.11 & 0.1 & 4 & 5 & 4 & 5 & 0.05 & \\
\hline
\end{tabular}

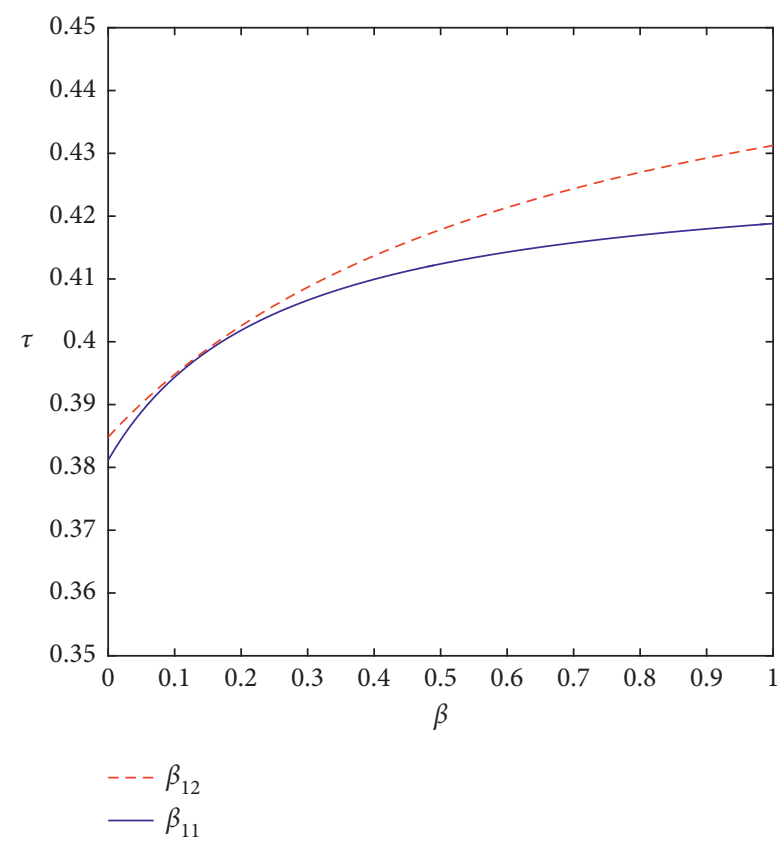

FIGURE 1: The relationship between the ecological compensation rate and green innovation investment cost coefficient.

investment cost, the greater the proportion of ecological compensation. For polluting enterprises or polluted areas, higher green innovation investment costs are not conducive to the improvement of pollution control technologies, and they are more inclined to accept investment ecological compensation from others. When the level of green innovation in the upstream region is low, a certain amount of investment ecological compensation is required from the downstream so that both the upstream and downstream of the basin can reach the optimal solution of the Nash equilibrium.

The proportion of ecological compensation increases as the transfer of pollutants increases. As shown in Figure 2, when the proportion of pollutants transferred from the upstream of the basin to the downstream increases, the proportion of investment compensation from the downstream to the upstream region will increase accordingly. Downstream regions try to reduce the pollution stock by transferring pollution control investment. Figure 3 shows the relationship between the transfer rate of the two pollutants and the ecological compensation rate, which also reflects this positive correlation. In addition, we can also see that the rate of change of this positive correlation is gradually decreasing. In the initial stage, when the amount of pollutants transferred is small, the amount of ecological compensation will increase rapidly. However, when the proportion of pollutant transfer in the upstream basin

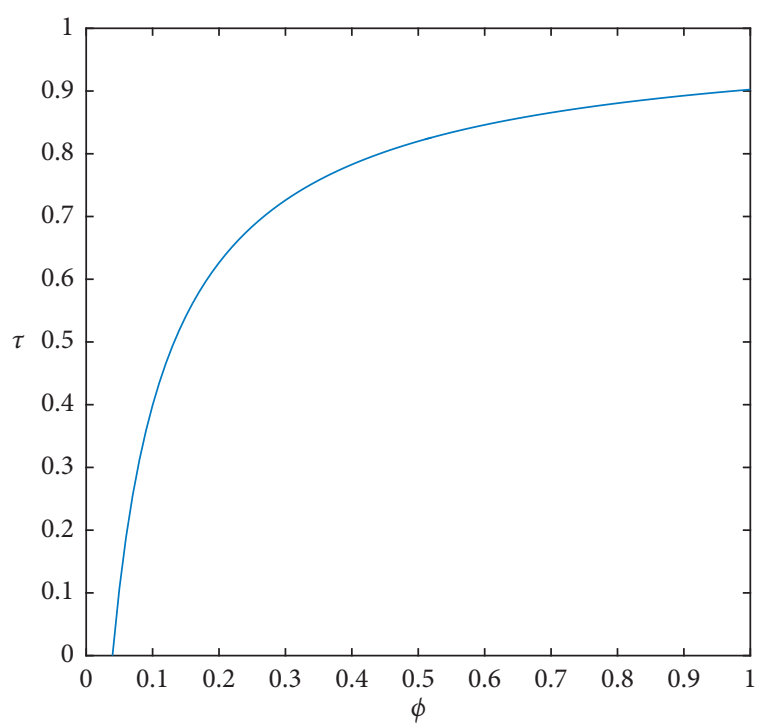

Figure 2: The two-dimensional relationship between the ecological compensation rate and pollution transfer coefficient.

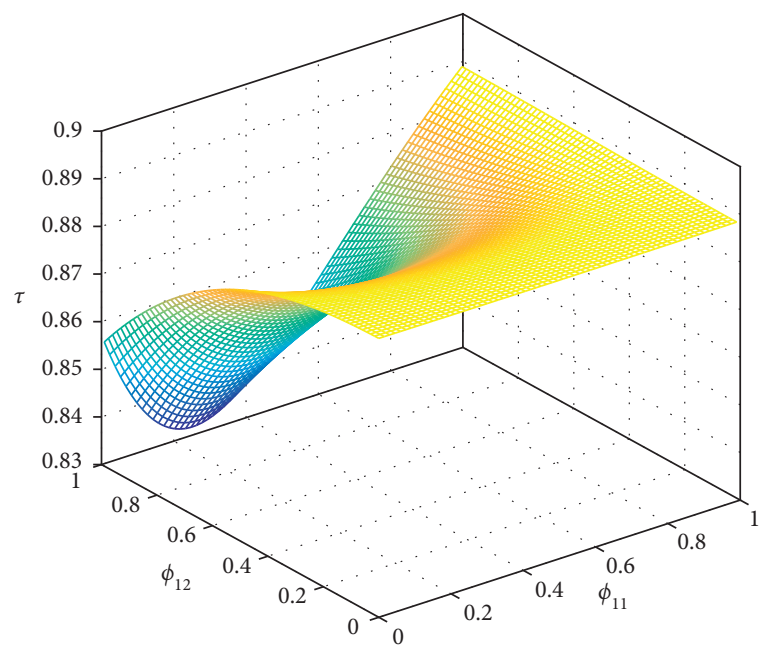

FIgURE 3: The three-dimensional relationship between ecological compensation rate and transfer coefficients of two pollutants.

gradually increases to a certain value, the rate of increase in ecological compensation will slow down. In other words, when a large amount of upstream pollutants are transferred to the downstream regions, downstream regions will no longer expect to reduce the stock of pollutants in the basin by transferring pollution control investment compensation, but may continuously increase the pollution control efforts in the region to change this situation.

There is a chain reaction relationship among the investment cost of green innovation, pollutant transfer rate, and ecological compensation rate. The increase of green innovation investment cost will promote the downstream region to increase the amount of ecological compensation to the upstream. Increasing the compensation rate of the downstream to the upstream will make the upstream increase the pollution control, which will reduce the amount of pollutants transferred to a certain extent. Conversely, the 
reduced transfer of pollutants will reduce the amount of compensation from the downstream to the upstream region. After such a game, a nonvirtuous circle is formed, which leads to the failure of cooperation in watershed pollution control, and ultimately is not conducive to the treatment of water pollution in the transboundary river basin.

Therefore, it is necessary to establish a joint mechanism composed of the government and the market and formulate a reasonable green innovation subsidy scheme according to the actual situation of the basin, so as to restrict the emergence of this "individual rational" behavior.

5.2. Comparative Analysis of Variables. Figures 4 and 5 show the change trajectory of the emission rate in upstream and downstream regions under the noncooperative decisionmaking model. It can be found that, in a certain period of time, the pollution control game of green innovation compensation is relatively stable, and the pollution emission rate of each region is relatively stable. With the development of noncooperative decision-making game, the game between the two sides tends to be not cooperative. The investment level of pollution control will also gradually increase, as shown in Figures 6 and 7, which will significantly increase the investment cost of pollution control in various regions. This result has caused the gradual accumulation of pollutants in the upstream and downstream regions of the basin. As shown in Figures 8 and 9, the water pollution situation continues to deteriorate. However, as the level of green innovation investment continues to increase, in the long term, the pollutant stock in the upstream and downstream of the basin will be restricted and tend to stabilize. It shows that the effect of green innovation investment is beginning to appear.

Under the model of cooperative decision-making, the upstream and downstream regions of the basin reach some agreement, set up a joint decision-making department or unified decision-making by a higher management department, and jointly coordinate the pollution discharge strategies of the two regions with the goal of maximizing the total net present value of long-term income. The cooperative decision-making model is different from noncooperative in that it can internalize environmental externalities and maximize welfare, as shown in Figures 10-15. The emission rate of pollutants in the river basin has been drastically reduced, the level of abatement investment in pollution control has also been reduced, and the level of pollution stock has been significantly reduced. Finally, the water pollution environment in the basin has been greatly improved.

The level of green innovation investment has not changed much, but the emission reduction effect brought by the continuous strengthening of green innovation investment is very obvious. As shown in Figures 14 and 15, the stock level of pollutants in the river basin becomes stable in a short period of time, and the stable state level is far below the stock under noncooperative game conditions.

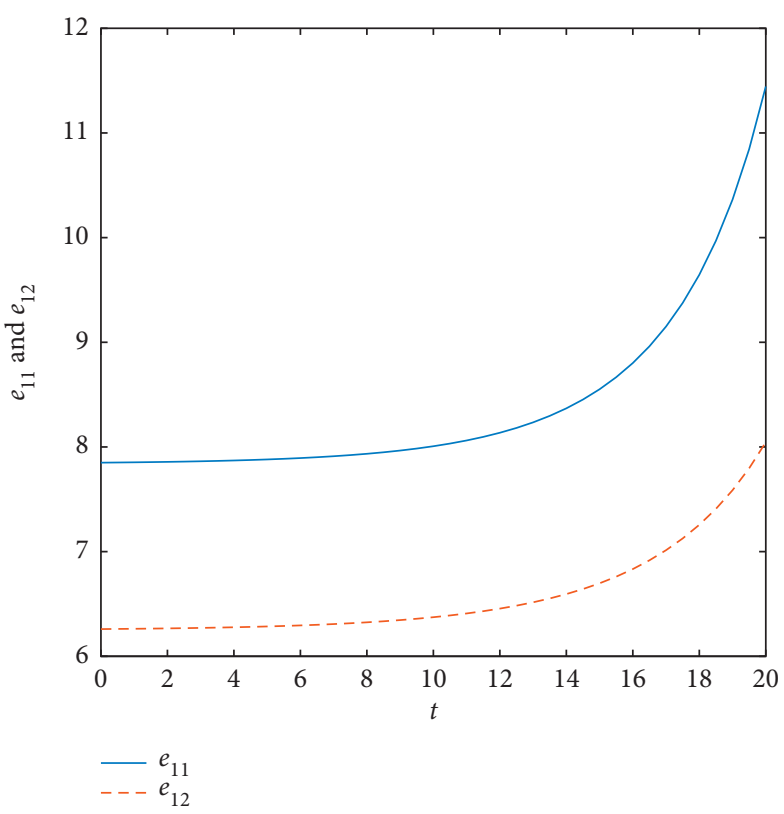

FIGURE 4: The pollution emission trajectory of the upstream region under noncooperation.

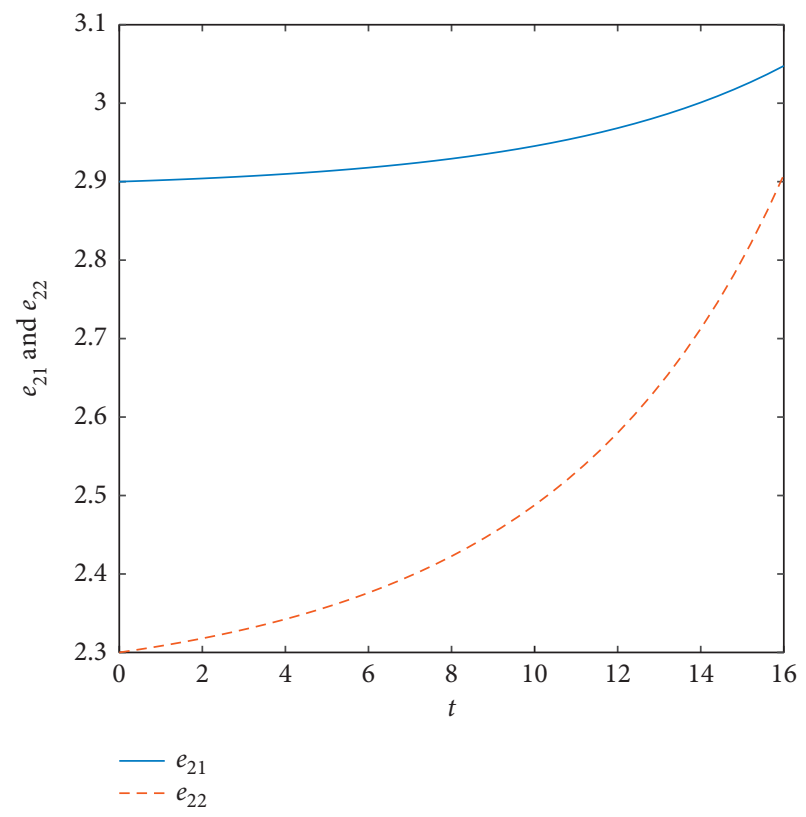

FIgURE 5: The pollution emission trajectory of the downstream region under noncooperation.

5.3. Comprehensive Analysis. In order to analyze the change trajectory of each variable more intuitively, we compare the results of two kinds of decision-making, namely, noncooperative and cooperative game decision-making, as shown in Figures 16 and 17. It can be seen that the investment governance level under the cooperative game decisionmaking model is slightly lower than that of the noncooperative game, as shown by the solid line in Figure 16. The 


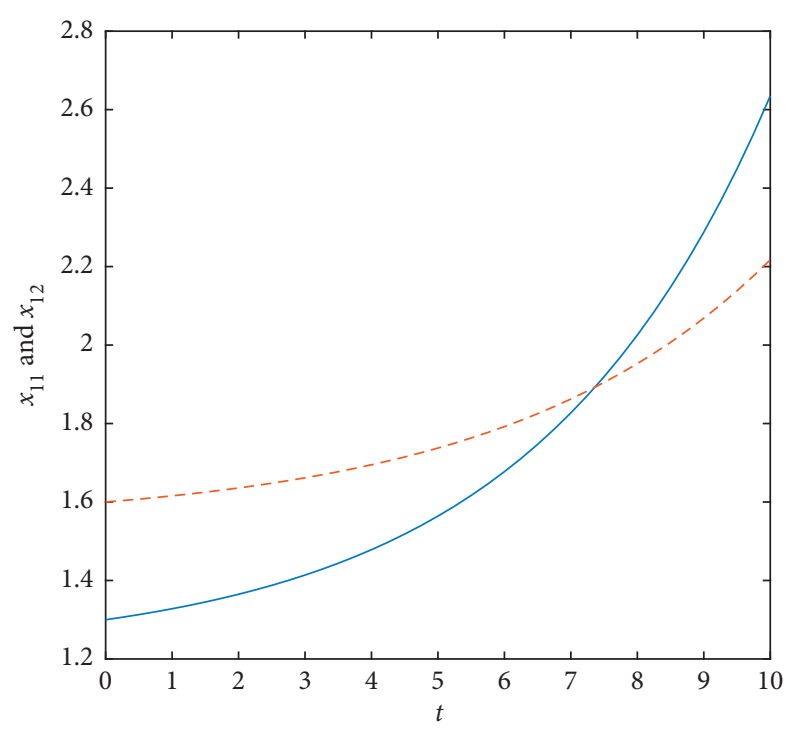

$\begin{aligned}- & x_{11} \\ --- & x_{12}\end{aligned}$

FIgURE 6: The pollution abatement investment trajectory of the upstream region under noncooperation.

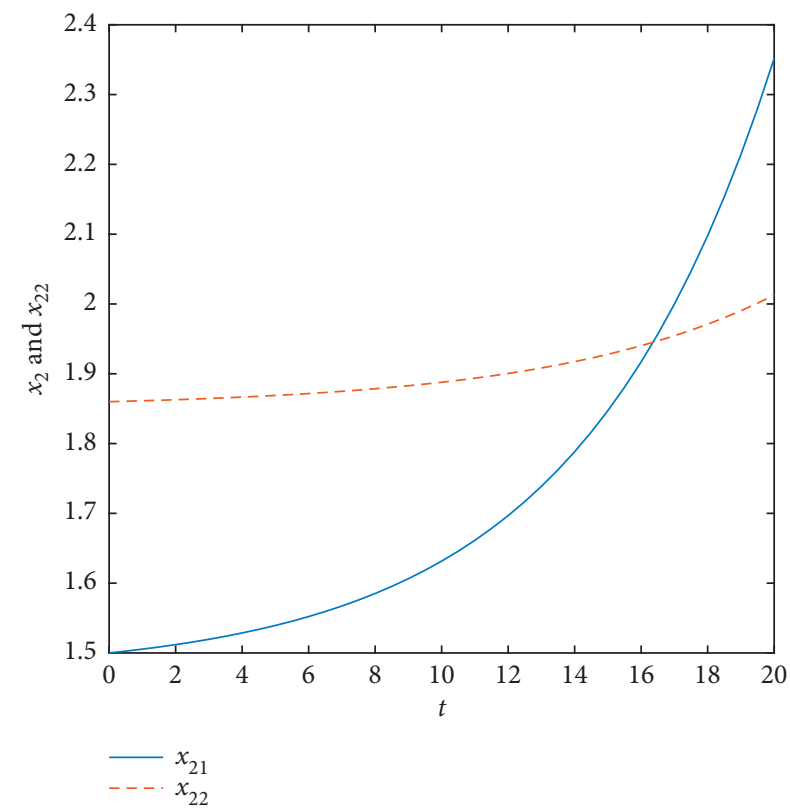

Figure 7: The pollution abatement investment trajectory of the downstream region under noncooperation.

pollution stock level, as shown by the solid line in Figure 17, is significantly lower than that of noncooperative game decision-making. This shows that although the cooperative game decision-making reduces the investment level of pollution abatement, it greatly reduces the pollution stock level in the basin and effectively improves the water environment quality.

5.4. Further Analysis. From the above comparative analysis, we found that the cooperative decision-making model is an

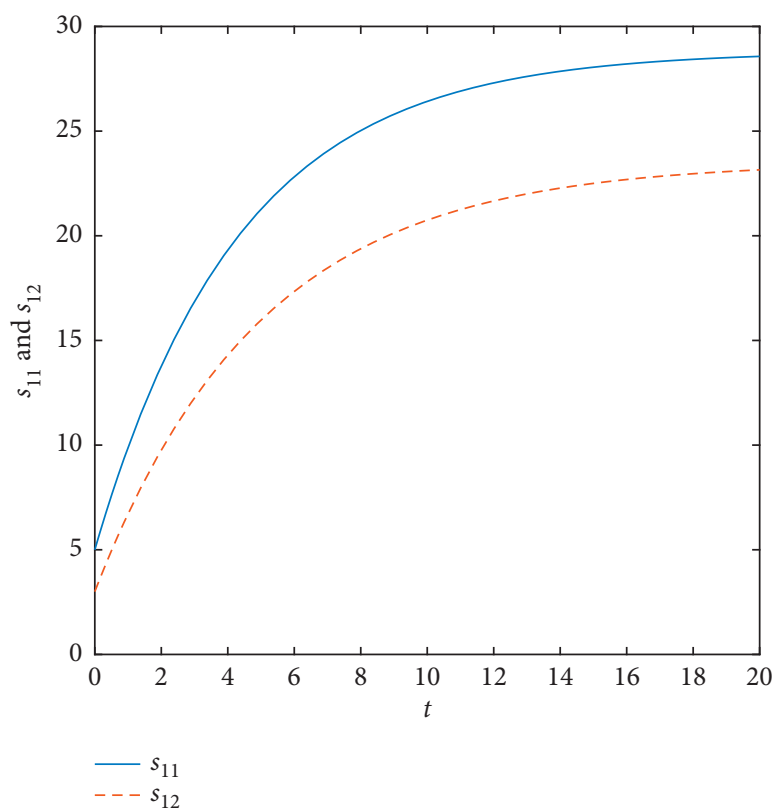

FIgURE 8: The pollution stock trajectory of the upstream region under noncooperation.

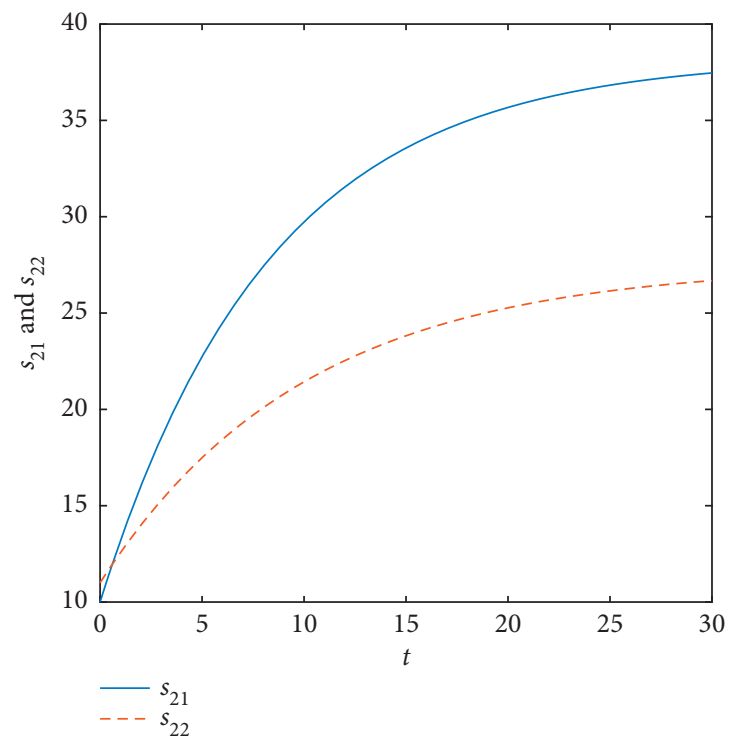

FIgURE 9: The pollution stock trajectory of the downstream region under noncooperation.

effective transboundary water pollution control model. On further analysis, we can also find that, in the steady state, the pollutant stock is inversely proportional to the ecological compensation rate, and this rate of change gradually becomes faster as the ecological compensation rate increases. It shows that the proportion of ecological compensation has a law similar to the increasing marginal utility. In Section 3, we obtain the Nash equilibrium solution of the ecological compensation rate in the noncooperative decision-making model; the optimal value is 0.41 by simulation, but it seems that this is not the optimal value of the ecological 


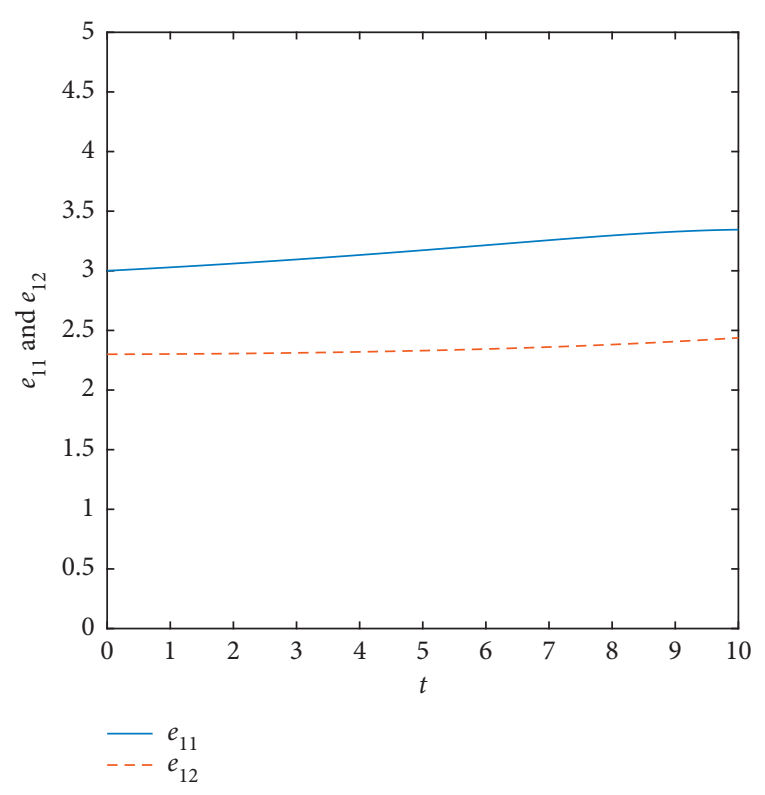

FIgURE 10: The pollution emission trajectory of the upstream region under cooperation.

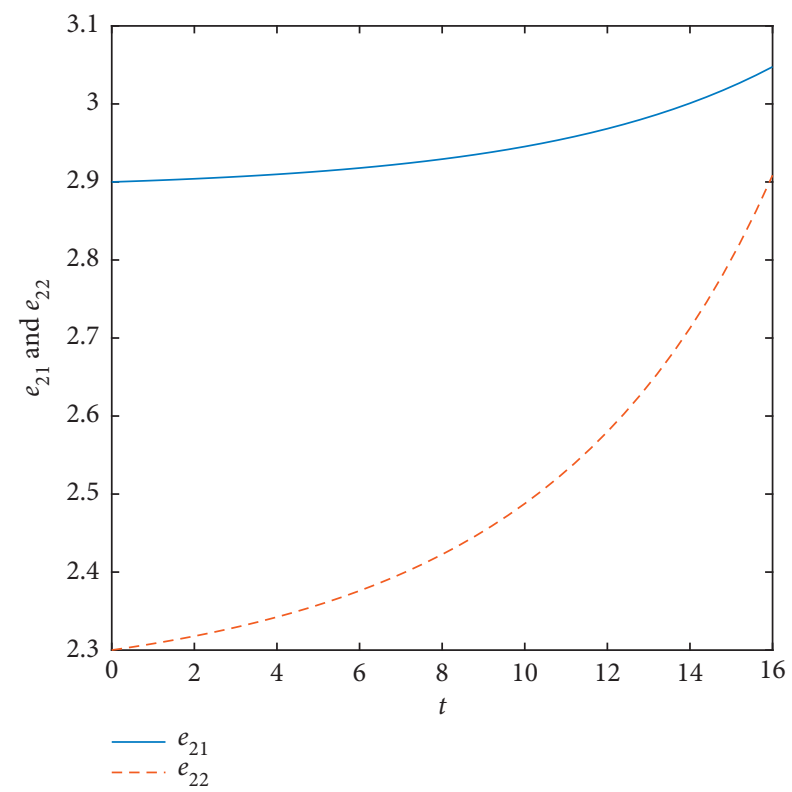

FIGURE 11: The pollution emission trajectory of the downstream region under cooperation.

compensation rate when the pollution stock can be reduced to a relatively low level. Therefore, we further calculate that if the pollution stock is reduced to the level of the cooperative decision-making model, as shown in Figure 18, the value of the ecological compensation rate at this time is about 0.8589 .

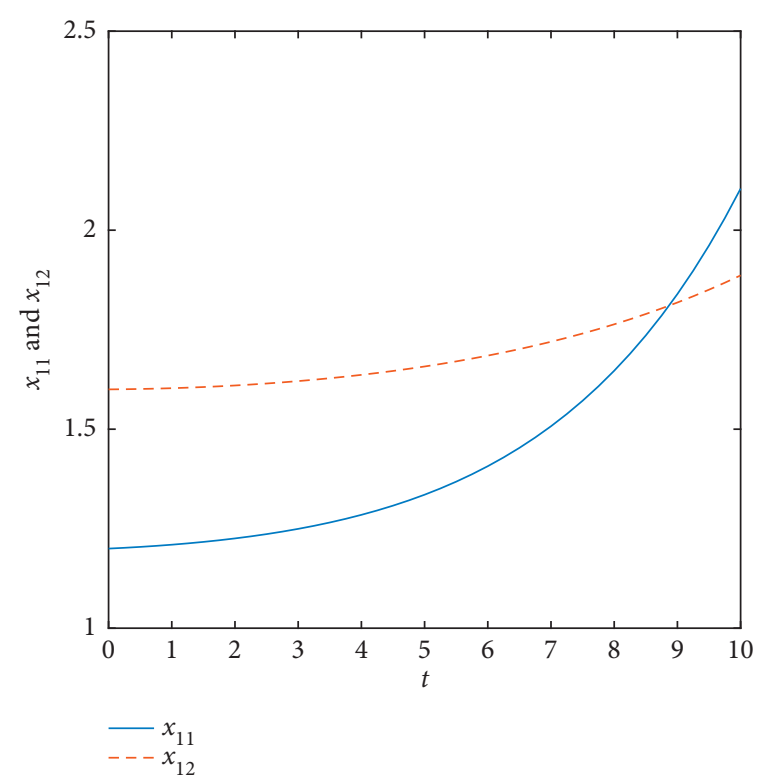

FIGURE 12: The pollution abatement investment trajectory of the upstream region under cooperation.

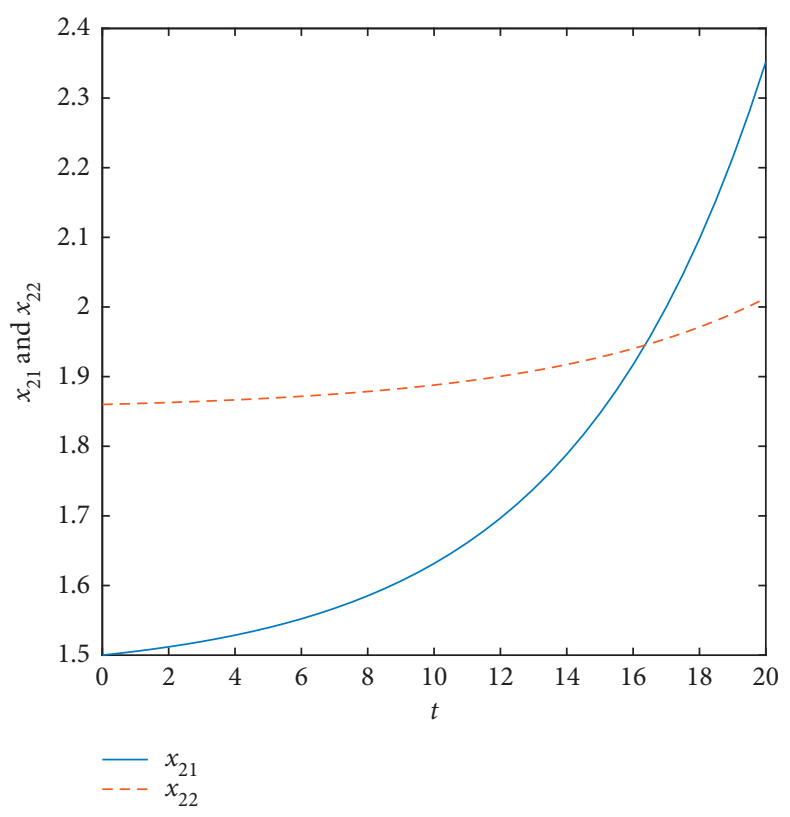

FIgURE 13: The pollution abatement investment trajectory of the downstream region under cooperation.

In other words, if the compensation rate under the noncooperative decision-making model is 0.8589 , the pollution stock in the basin can also drop to a relatively low level. 


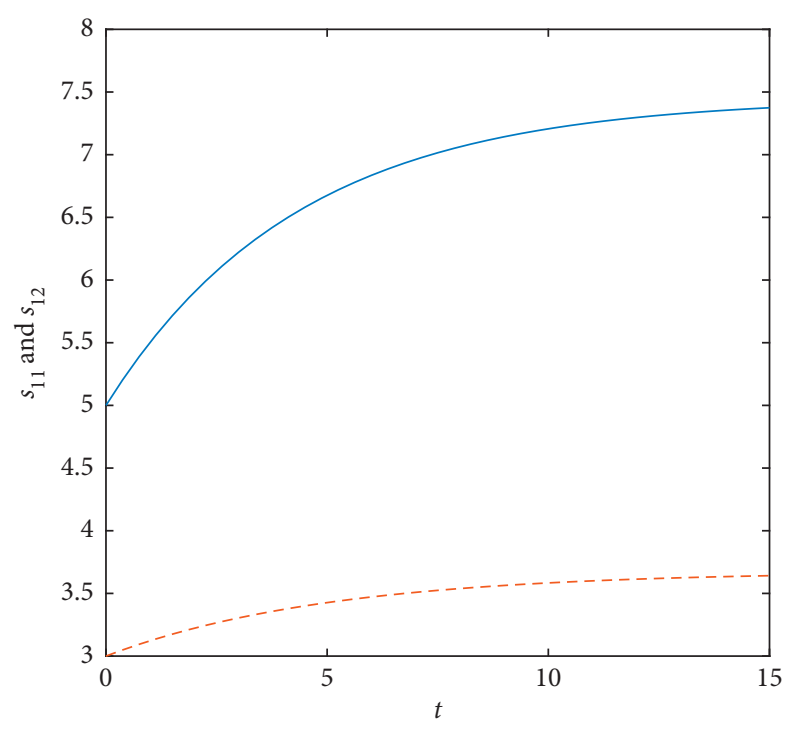

$$
\begin{aligned}
- & s_{11} \\
--- & s_{12}
\end{aligned}
$$

FIGURE 14: The pollution stock trajectory of the upstream region under cooperation.

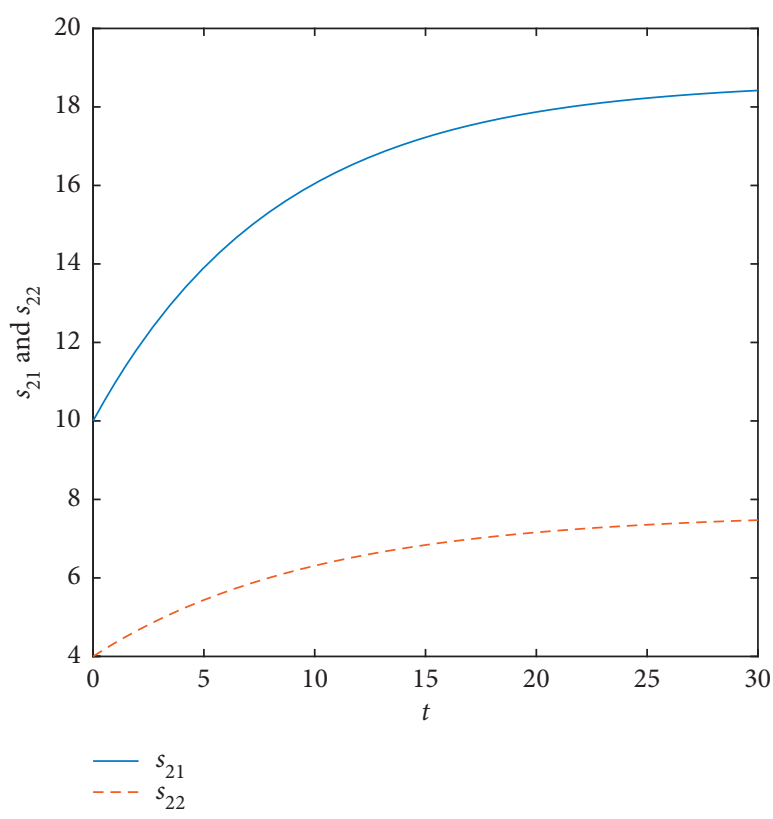

FIGURE 15: The pollution stock trajectory of the downstream region under cooperation.

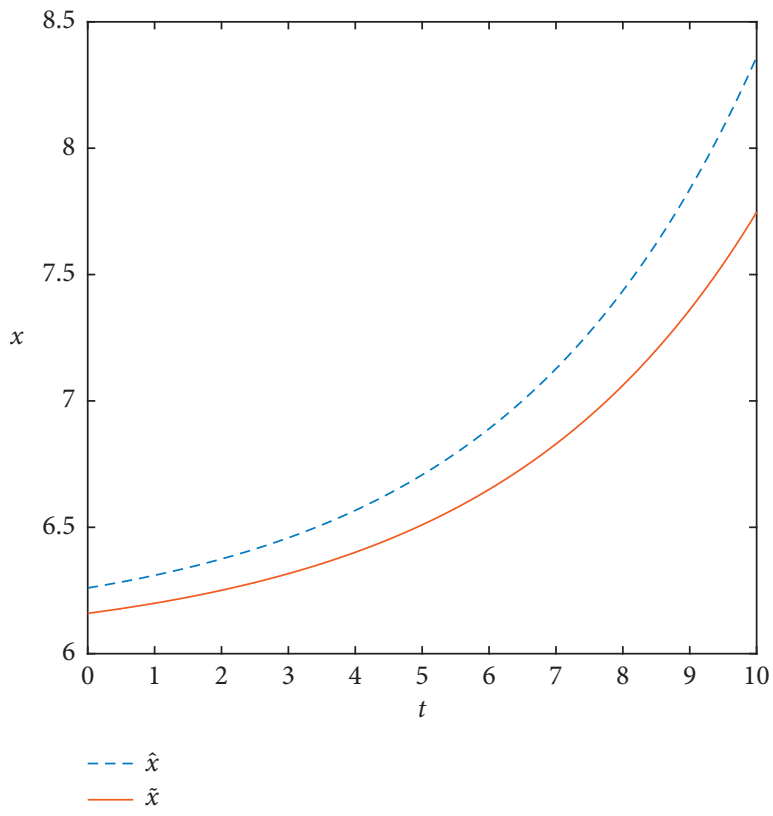

Figure 16: The pollution abatement investment trajectory of both regions under noncooperation and cooperation.

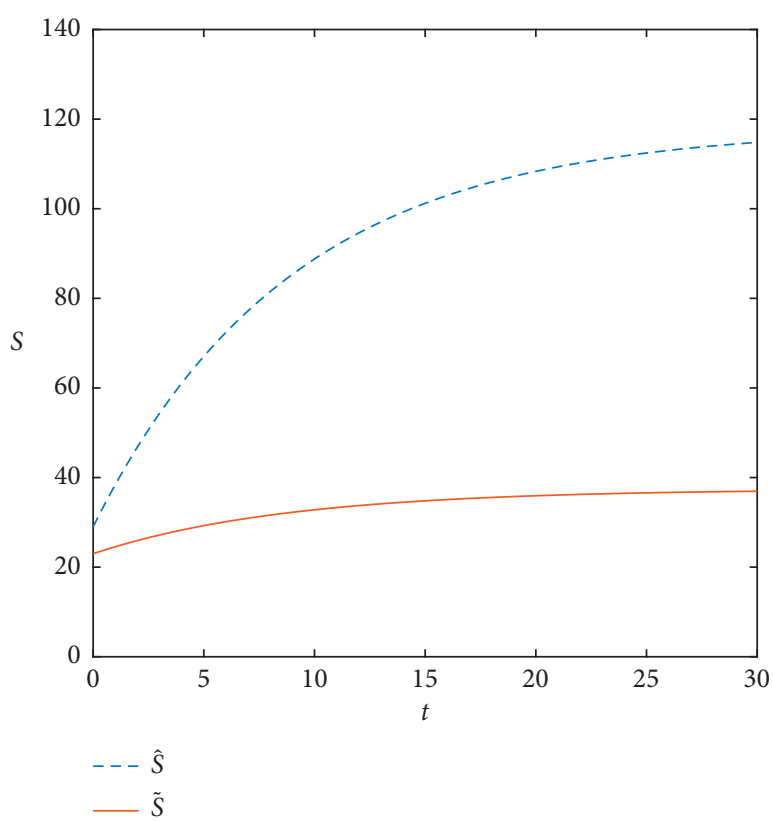

FIgURE 17: The pollution stock trajectory of both regions under noncooperation and cooperation. 


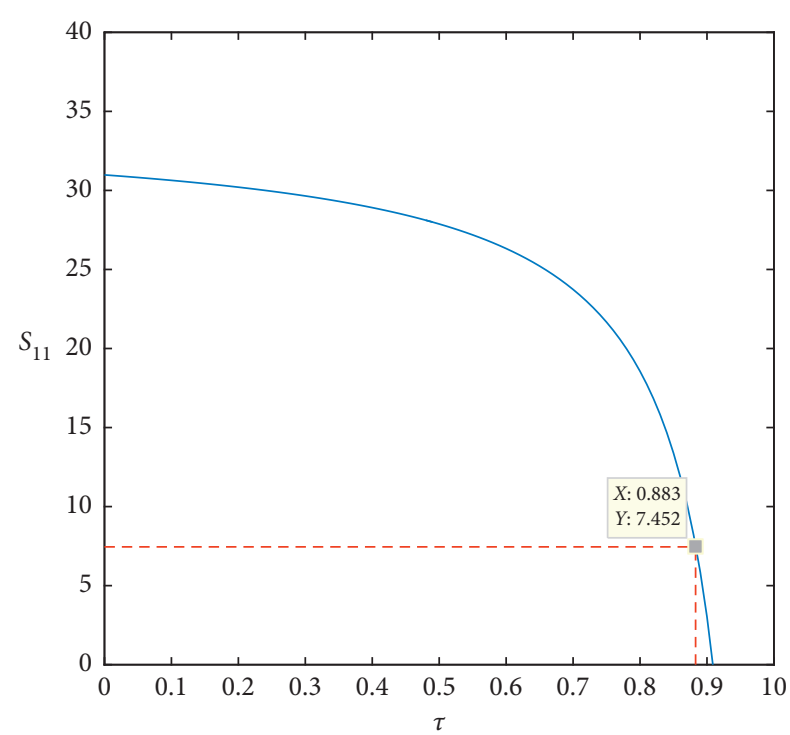

FIGURE 18: The relationship between pollution stock and ecological compensation rate.

\section{Conclusions and Policy Recommendations}

6.1. Main Conclusions. This article mainly studies the decision-making of transboundary water pollution control under the premise of multiple pollutants. Among them, it also includes the determination of the green innovation compensation rate and the analysis of influencing factors. We established a differential game model to solve the optimal Nash equilibrium solution, used numerical simulation to measure and analyze the change trajectory of various variables in cooperative and noncooperative decisionmaking models, and obtained the optimal green innovation compensation rate value in the noncooperative model. In addition, we further discussed the improvement of the compensation rate.

The investment cost of green innovation is directly proportional to the ecological compensation rate. In the game of transboundary river basins, the investment cost of pollution control in the downstream is the key factor to determine the compensation to the upstream region. The higher the investment cost of green innovation, the greater the ecological compensation rate; otherwise, the lower. In addition, the rate of ecological compensation is also affected by the amount of pollutants transferred. When the proportion of pollutants transferred from the upstream to downstream becomes larger, the proportion of investment compensation from the downstream to the upstream region will increase accordingly. On the contrary, increasing the proportion of compensation to the upstream in the downstream area will make the upstream increase the pollution control, which will reduce the amount of pollutants transferred to a certain extent. The nonvirtuous chain reaction between green innovation investment cost, pollutant transfer rate, and ecological compensation rate is not conducive to the orderly progress of transboundary water pollution control in the river basin.
6.2. Policy Recommendations. Regarding the direct proportional relationship between the green innovation subsidy rate, the green innovation investment cost, and the pollution transfer coefficient, local regulatory agencies in the basin must consider both the cost of innovation investment and the amount of pollutants transferred. In order to achieve the optimal management goals, it is necessary to ensure that the upstream and downstream of the basin can reach the optimal Nash equilibrium.

In order to deal with the nonvirtuous chain reaction between green innovation investment cost, pollutant transfer rate, and ecological compensation rate and to ensure that the transboundary water pollution of the river basin can be effectively and cooperatively controlled, this requires the use of regulatory policies to intervene to encourage the downstream regions to increase the proportion of ecological compensation and form a stable transfer mechanism. To a certain extent, the downstream will not reduce the amount of ecological compensation to the upstream region due to the reduction of pollutant transfer. Therefore, it is necessary to establish a joint mechanism composed of the government and the market and formulate a reasonable green innovation subsidy scheme according to the actual situation of the basin, so as to restrict the emergence of this "individual rational" behavior.

For two adjacent regions with transboundary water pollution problems, if cross-regional unified cooperation cannot be achieved, ecological investment compensation is also a good choice that can effectively alleviate regional pollution. The level of innovation investment under noncooperative decision-making is also relatively high, and to a certain extent, it can also reduce pollutant emissions and facilitate the improvement of clean technology. For river basin areas that can establish a unified management department and organize the implementation of decisionmaking, cooperative game is a very effective pollution control decision. It can use less innovation investment to reduce the emission of pollutants. At the same time, in a steady state, the pollution stock level of the basin drops a lot compared with noncooperative decision-making.

In addition, the central government should strengthen the modern management of the river basin, improve the transboundary water pollution prevention and control system, establish a new cooperation mechanism for the prevention and control of transboundary water pollution, promote the construction of the upstream and downstream coordination platform, and promote the organic integration and cooperation in the operation process of the coordination mechanism of various river basin management agencies, so as to reduce the transaction cost. Relevant government departments should speed up the market-oriented construction of river basin transboundary water pollution control, innovate the market-oriented mode of transboundary ecological compensation, improve the river basin emission permit system and trading system, strengthen the multiparticipation mechanism of the river basin, and strengthen information disclosure and public participation. River basin management organizations should strengthen publicity and education, enhance the awareness of 
environmental protection of citizens in the river basin, and advocate resource-saving and environment-friendly production and living technologies.

\section{Data Availability}

The data used to support the findings of this study are included within the article.

\section{Conflicts of Interest}

The authors declare that they have no conflicts of interest regarding the publication of this paper.

\section{Acknowledgments}

This work was supported by the National Social Science Foundation of China (Grant no. 18ZDA040), Humanities and Social Science Foundation of the Ministry of Education of China (Grant no. 17JJD790017), and the Hunan Provincial Social Science Outcomes Review Committee Major Projects (Grant no. XSP20ZDA007).

\section{References}

[1] E. J. Dockner, S. Jorgensen, and N. V. Long, Differential Games in Economics and Management Science: Introduction, Cambridge Books, Cambridge, UK, 2000.

[2] S. S. Sana, "The EOQ model-A dynamical system," Applied Mathematics \& Computation, vol. 218, pp. 8736-8749, 2012.

[3] S. Jorgensen and G. Zaccour, "A survey of game-theoretic models of cooperative advertising," European Journal of Operational Research, vol. 237, no. 1, pp. 1-14, 2014.

[4] F. Cabo, G. Martin-Herran, and M. P. Martinez-Garcia, "Property rights for natural resources and sustainable growth in a two-country trade model," Decisions in Economics \& Finance, vol. 37, no. 1, pp. 99-123, 2014.

[5] G. Janssens and G. Zaccour, "Strategic price subsidies for new technologies," Automatica, vol. 50, no. 8, pp. 1999-2006, 2014.

[6] S. S. Shib, "Optimal sales team's initiatives and pricing of pharmaceutical products," International Journal of Systems Science: Operations \& Logistics, vol. 2, pp. 168-176, 2015.

[7] P. Andres-Domenech, G. Martin-Herran, and G. Zaccour, "Cooperation for sustainable forest management: an empirical differential game approach," Ecological Economics, vol. 117, pp. 118-128, 2015.

[8] L. A. Petrosyan and G. Zaccour, "Cooperative differential games with transferable payoffs," in Handbook of Dynamic Game Theory, T. Basar and G. Zaccour, Eds., Springer, Cham, Switzerland, 2016.

[9] M. Bhattacharyya and S. S. Sana, "A mathematical model on eco-friendly manufacturing system under probabilistic demand,” RAIRO-operations Research, vol. 53, p. 5, 2018.

[10] A. Roy, S. S. Sana, and K. Chaudhuri, "Optimal Pricing of competing retailers under uncertain demand-a two layer supply chain model," Annals of Operations Research, vol. 260, pp. 1-2, 2018.

[11] S. S. Sana, "Price competition between green and non green products under corporate social responsible firm," Journal of Retailing and Consumer Services, vol. 55, Article ID 102118, 2020.
[12] S. S. Sana, "A structural mathematical model on two echelon supply chain system," Annals of Operations Research, vol. 27, pp. 1-29, 2021.

[13] F. Ploeg, A. van der, and J. de Zeeuw, "International aspects of pollution control," Environmental and Resource Economics, vol. 2, pp. 117-139, 1992.

[14] N. V. Long, "Pollution control: a differential game approach," Annals of Operations Research, vol. 37, pp. 283-296, 1992.

[15] E. J. Dockner and N. V. Long, "International pollution control: cooperative versus noncooperative strategies," Journal of Environmental Economics and Management, vol. 25, pp. 13-29, 1993.

[16] L. Petrosyan and G. Zaccour, "Time-consistent shapley value allocation of pollution cost reduction," Journal of Economic Dynamics and Control, vol. 27, pp. 381-398, 2003.

[17] S. Jørgensen and G. Zaccour, "Incentive equilibrium strategies and welfare allocation in a dynamic game of pollution control," Automatica, vol. 37, pp. 29-36, 2001.

[18] D. W. Yeung, "Dynamically consistent cooperative solution in a differential game of transboundary industrial pollution," Journal of Optimization Theory and Applications, vol. 134, no. 1, pp. 143-160, 2007.

[19] D. W. Yeung and L. A. Petrosyan, "A cooperative stochastic differential game of transboundary industrial pollution," Automatica, vol. 44, no. 6, pp. 1532-1544, 2008.

[20] H. Benchekroun and G. Martín-Herran, "The impact of foresight in a transboundary pollution game," European Journal of Operational Research, vol. 251, no. 1, pp. 300-309, 2016.

[21] S. D. Li, "A differential game of trans-boundary industrial pollution with emission permits trading," Journal of Optimization Theory and Applications, vol. 163, pp. 642-659, 2014.

[22] X. Huang, P. He, and W. Zhang, “A cooperative differential game of transboundary industrial pollution between two regions," Journal of Cleaner Production, vol. 120, pp. 43-52, 2016.

[23] S. Chang, W. Qin, and X. Wang, "Dynamic optimal strategies in transboundary pollution game under learning by doing," Physica A, vol. 490, pp. 139-147, 2018a.

[24] H. Benchekroun and A. R. Chaudhuri, "Transboundary pollution and clean technologies," Resource and Energy Economics, vol. 36, no. 2, pp. 601-619, 2014.

[25] N. D. Hall, "Transboundary pollution: harmonizing international and domestic law," University of Michigan Journal of Law Reform, vol. 40, p. 681, 2006.

[26] O. Tahvonen, "Carbon dioxide abatement as a differential game," European Journal of Political Economy, vol. 10, no. 4, pp. 685-705, 1994.

[27] S. B. Youssef, "Transboundary pollution, R\&D spillovers and international trade," The Annals of Regional Science, vol. 43, no. 1, pp. 235-250, 2009.

[28] Y. Yi, R. Xu, and S. Zhang, "A differential game of R\&D investment for pollution abatement in different market structures," Physica A: Statistical Mechanics and Its Applications, vol. 524, pp. 587-600, 2019.

[29] Y. Yi, Z. Wei, and C. Fu, "A differential game of transboundary pollution control and ecological compensation in a river basin," Complexity, vol. 2020, Article ID 6750805, , 2020.

[30] Z. Chen, R. Xu, and Y. Yi, "Dynamic optimal control of transboundary pollution abatement under learning-by-doing depreciation," Complexity, vol. 2020, Article ID 3763684,, 2020.

[31] W. Shang, Y. Gong, Z. Wang, and M. J. Stewardson, "Ecocompensation in China: theory, practices and suggestions for 
the future," Journal of Environmental Management, vol. 210, pp. 162-170, 2018.

[32] J. Kangas and M. Ollikainen, "Economic insights in ecological compensations: market analysis with an empirical application to the Finnish economy," Ecological Economics, vol. 159, pp. 54-67, 2019.

[33] K. Jiang, D. You, Z. D. Li, and S. S. Shi, "A differential game approach to dynamic optimal control strategies for watershed pollution across regional boundaries under eco-compensation criterion," Ecological Indicators, vol. 105, pp. 229-241, 2019.

[34] K. J. Arrow, "The economic implications of learning by doing," The Review of Economic Studies, vol. 29, pp. 155-173, 1962.

[35] S. D. Li and X. J. Pan, "A dynamic general equilibrium model of pollution abatement under learning by doing," Economics Letters, vol. 122, pp. 285-288, 2014.

[36] Z. Wei, Y. X. Yi, and C. Y. Fu, "Cournot competition and "green" innovation under efficiency-improving learning by doing," Physica A, vol. 531, pp. 121-132, 2019.

[37] E. H. Grosse, C. H. Glock, and S. Mueller, "Production economics and the learning curve: a meta-analysis," International Journal of Production Economics, vol. 170, pp. 401412, 2015.

[38] H. Li and G. Guo, "A differential game analysis of multipollutant transboundary pollution in river basin," Physica A: Statistical Mechanics and Its Applications, vol. 535, 2019.

[39] L. Lambertini and A. Mantovani, "On the (in)stability of nonlinear feedback solutions in a dynamic duopoly with renewable resource exploitation," Economics Letters, vol. 143, pp. 9-12, 2016.

[40] M. Guiomar and S. J. Rubio, "Second-best taxation for a polluting monopoly with abatement investment," The Review of Economic Studies, vol. 73, no. 6, pp. 178-193, 2018.

[41] L. Fernandez, "Trade's dynamic solutions to transboundary pollution," Journal of Environmental Economics and Management, vol. 43, no. 3, pp. 386-411, 2002.

[42] S. Chang, S. P. Sethi, and X. Wang, "Optimal abatement and emission permit trading policies in a dynamic transboundary pollution game," Dynamic Games and Applications, vol. 8, pp. 542-572, 2018.

[43] Z. Chen, R. Xu, and Y. Yi, "A differential game of ecological compensation criterion for transboundary pollution abatement under learning by doing," Discrete Dynamics in Nature and Society, vol. 2020, Article ID 7932845, 2020. 